\title{
Kenya and Ethiopia: Community and religious leaders are effective advocates for HIV testing for young couples
}

Population Council

Follow this and additional works at: https://knowledgecommons.popcouncil.org/departments_sbsr-rh

Part of the Demography, Population, and Ecology Commons, Family, Life Course, and Society Commons, Gender and Sexuality Commons, International Public Health Commons, Medicine and Health Commons, and the Sociology of Religion Commons How does access to this work benefit you? Let us know!

\section{Recommended Citation}

"Kenya and Ethiopia: Community and religious leaders are effective advocates for HIV testing for young couples," FRONTIERS OR Summary. Washington, DC: Population Council, 2008. 
Kenya, Ethiopia Integration

OR Summary 80

\section{Community and Religious Leaders Are Effective Advocates for HIV Testing for Young Couples}

\begin{abstract}
Community-based strategies to improve access to HIV information and services by married adolescents were acceptable to communities in Ethiopia and Kenya and significantly improved access to HIV counseling and testing. Related projects by the Population Council and other agencies are utilizing findings from this study in projects for marginalized youth in Ethiopia.
\end{abstract}

\section{Background}

Early marriage is common for girls - in much of sub-Saharan Africa; the majority are married before age 19, and much younger in some countries. A common belief is that marriage protects them from HIV, but studies show that married girls, who are likely to have more unprotected sex than their unmarried counterparts, are at much higher risk from HIV as well as from maternal morbidity and mortality. Young married girls also tend to have less access to reproductive health information and services.

FRONTIERS conducted operations research in Ethiopia and Kenya to assess the acceptability and feasibility of community-based interventions to raise awareness of the HIV risks of early marriage and promote the use of HIV counseling and testing (C\&T) services by couples. The studies were an initial phase in a planned four-year intervention; this summary reports on the feasibility of the approach.

The Ethiopia study (2006-2008) was conducted, in partnership with the Ethiopian Orthodox Church and the Ethiopian Muslim Development Agency, in the mainly rural Amhara region, which accounts for about one-third of the country's existing, new, and antenatal HIV infections. The Kenya intervention (2005-2008) was conducted in partnership with the Program for Appropriate Technology in Health (PATH) and the Kendu Adventist Hospital in two districts of Nyanza Province, which has the highest HIV prevalence in Kenya.

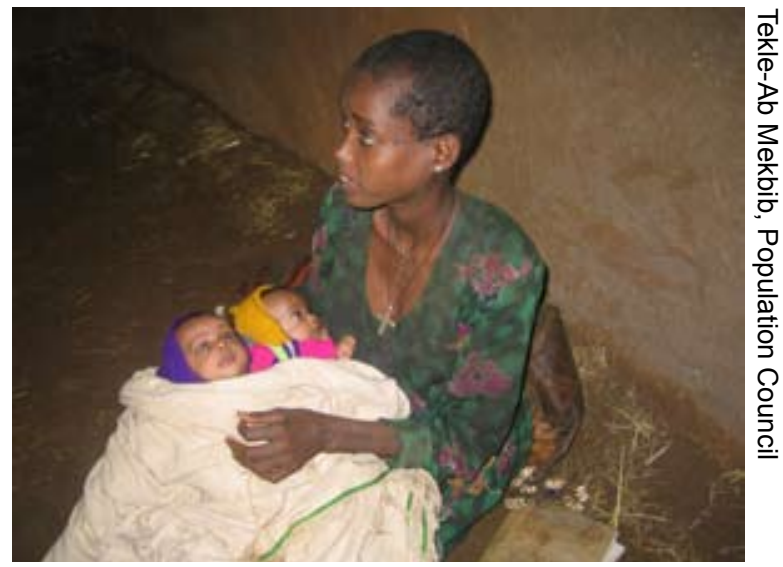

A member of the Married Girls' Club in Amhara with her twins.

Both interventions used similar strategies including: (1) engaging community and religious leaders in outreach campaigns; (2) promoting premarital C\&T and, if necessary, antiretroviral services for couples; and (3) supporting young wives through married girls' clubs and a mentoring program. The Kenya study also included theater performances through PATH's Magnet Theater program, and local-language radio spots with messages on the risks of early marriage as well as family planning information and other reproductive health messages.

In Ethiopia, over 1,200 priests and imams, 200 community health workers and community-based health agents, were trained to conduct outreach on HIV and early marriage. Fifty women - teachers or women's leaders - were trained to facilitate the girls' club meetings. In Kenya, cascade train- 
ing was used to train 26 community leaders, 90 female mentors, 60 religious leaders, 115 community health workers, and 882 caregivers for individuals with HIV. Data were gathered through record-keeping systems developed for the projects, and through facility statistics, interviews with stakeholders and participants, and analysis of quantitative and qualitative surveys.

\section{Findings}

- The community outreach strategy was very well accepted in both countries. In the very remote, low-infrastructure community where the intervention was tested in Ethiopia, the focus on adolescent girls had the effect of raising their status in their communities. The girls became important sources of reproductive health and HIV information among their extended families.

- Religious leaders were very effective advocates, reaching over 900,000 people in Ethiopia and over 17,000 community members in Kenya. The religious leaders also made more than 1,100 referrals for $\mathrm{C} \& \mathrm{~T}$ services.

- About 16,000 couples in Kenya jointly attended HIV testing services. In Kenya, a coupon system encouraged community members to use $C \& T$ services. (Numbers in Ethiopia were difficult to obtain because of initial misunderstandings about data-gathering.)

- Multimedia outreach was a major means of advocacy in Kenya. Fourteen groups conducted theater performances on marriage, HIV risks, and premarital C\&T that reached nearly 50,000 men and women. The performers offered coupons for couples who wished to be tested. Seven radio spots on HIV and marriage were aired on two stations, reaching an estimated 300,000 to 500,000 community members.

- The clubs and mentoring schemes reached over 16,000 married girls in Ethiopia. In Kenya, the Kendu Adventist Hospital supported mentors' attendance at meetings. The mentors conducted meetings where they discussed HIV (attended by over 7,600 girls), sexually transmitted infections (6,300 girls), C\&T (6,800 girls), and antiretroviral treatment (2,500 girls).

- Interviews and discussions showed that young married girls face significant domestic violence. As a result, sexual and gender based violence topics were included in mentoring sessions for girls' clubs as well as in discussions with husbands or partners of adolescents.

\section{Utilization}

- CARE and EngenderHealth have designed programs for married adolescent girls based on the Ethiopia study. The Population Council is using data from the initial study in a four-year program on marginalized and vulnerable girls in Ethiopia, including married adolescents, domestic workers, and migrants.

\section{Policy Implications}

- Addressing the reproductive health needs of adolescent wives is an important strategy for preventing HIV.

- Religious leaders can be effective community educators on young women's health risks, including HIV, early childbirth, and domestic violence.

December 2008

Sources: Erulkar, Annabel and Tekle Ab Mekbib. 2008. "Improving reproductive health and HIV prevention among married adolescents in Amhara, Ethiopia," FRONTIERS Final Report. Washington, DC: Population Council, See Also: Erulkar, Annabel and Bentinck Ochieng. 2008. "Highlighting marital HIV risk and promoting VCT in Nyanza, Kenya," FRONTIERS Final Report. Washington, DC: Population Council. Available on our website atwww.popcouncil.org/frontiers or by e-mail: frontiers@popcouncil.org

This publication is made possible by the generous support of the American people through the President's Emergency Plan for AIDS Relief (PEPFAR) and the United States Agency for International Development (USAID) under the terms of Cooperative Agreement No. HRN-A00-98-00012-00. The contents are the responsibility of the FRONTIERS Program and do not necessarily reflect the views of USAID or the United States Government.

\section{Population Council}

